\title{
STUDENT COMPUTER LABORATORIES WITH OPEN SOURCE TECHNOLOGIES
}

\author{
Fahri ÇAKAR ${ }^{1}$, Burhan SEVEN ${ }^{2}$, İsa ATAŞ ${ }^{3}$, Hayri YILDIRIM ${ }^{4}$ \\ ${ }^{1}$ Diyarbakır Technical Science Vocational School / DicleUniversity, Turkey \\ ${ }^{2}$ Diyarbakır Technical Science Vocational School / DicleUniversity, Turkey \\ ${ }^{3}$ Diyarbakır Technical Science Vocational School / DicleUniversity, Turkey \\ ${ }^{4}$ Diyarbakır Technical Science Vocational School / DicleUniversity, Turkey \\ * Corresponding author; E-mail: fcakar@dicle.edu.tr
}

\begin{abstract}
The increasing number of students, of course, also increases their costs. In fact, most of the expenditures are unnecessary. We can cost our laboratories, which we allocate quite a lot of budget, cheaper.

For this purpose, we can use ARM based, single board small computers. Their price is very low. However, they are quite sufficient for our work. We can equip these devices with operating systems free of charge with open source software.

We set up a test lab with 10 people for this, for testing. 10 people were working in our normal laboratory, also. We compared working convenience, productivity, working time and costs.

Despite the high cost in normal laboratories, there was a more comfortable and enjoyable work environment in our test lab. We have worked more enthusiastically in our lab with open source software and devices. So we saw that it was more efficient.

Key words: Open Source, Freeware, Internet Of Things, ARM, Single Board Computer
\end{abstract}

\section{INTRODUCTION :}

Every year the number of students is increasing. The schools where these students are studying are beginning to be inadequate. The cost of the application laboratories is high, making it difficult to implement them in schools. Most of the time, every student does not fall into a computer. Because the budget of the universities is limited and preparing the environment for such a student is heavy on the budget.

As costs increase, we give up some things. For example, we can not research smart home solutions. Our students read many technologies only in the articles. However, they do not have the opportunity to examine them closely and understand them.

In that case, we need to think about other alternatives. For example, we can complete our laboratories using small but capable devices developed recently. 
When we do a little research on this, my confusion comes with amazing results. Computers on the size of a credit card, less electricity-consuming communication technologies, and many more.

Most of these single board small computers use an ARM-based processor. We see them mostly used in mobile systems, embedded systems, intelligent traffic junctions, control of some external devices and smart home solutions. The storage units they use as disks are an SD card. All other components are located on a single board.

We can design a laboratory using these devices and we can do the following with our students:

- Identification and use of different operating systems

- Creation of small server computers

- Radio and television broadcasts

- Software development and training

- Advertising and web design

- Electrical and electronic education

- Practical uses such as a movie player

- Developing smart home solutions

- Development of coding and design skills for young children

\section{MATERIALS AND METHODS}

\subsection{Identification of Used Material}

To set up the laboratory we think, let's first look at what the material should be in a normal laboratory. After then let's consider the technology that will take their place.

- At least one intelligent switch

- Cables that connect computers to the network

- Computers (Desktop or Laptop)

- Electrical cables and sockets

- Licenses for the Windows Operating System and the installed software

These increase the cost. It takes up a lot of space in the lab. On each side, there is cable clutter and a frequently distorted structure. Really big rooms are needed for these. But it will still be a complex structure. As in Figure 1. 
$$
\text { (1) }
$$

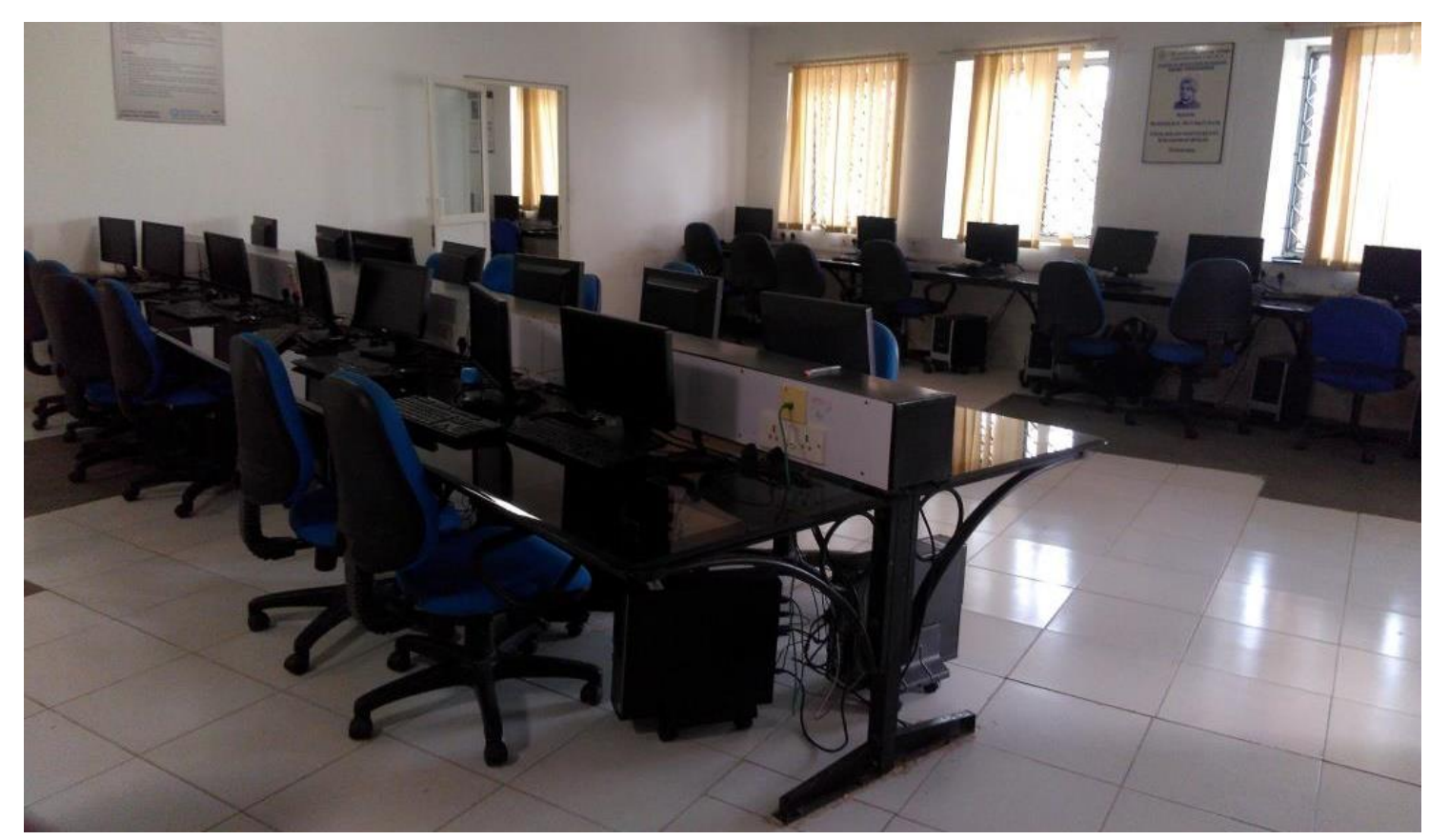

Figure 1 : The appearance of a classical computer lab.

We opened someone's locker out of these computers. The image in Figure 2 was the cleanest.

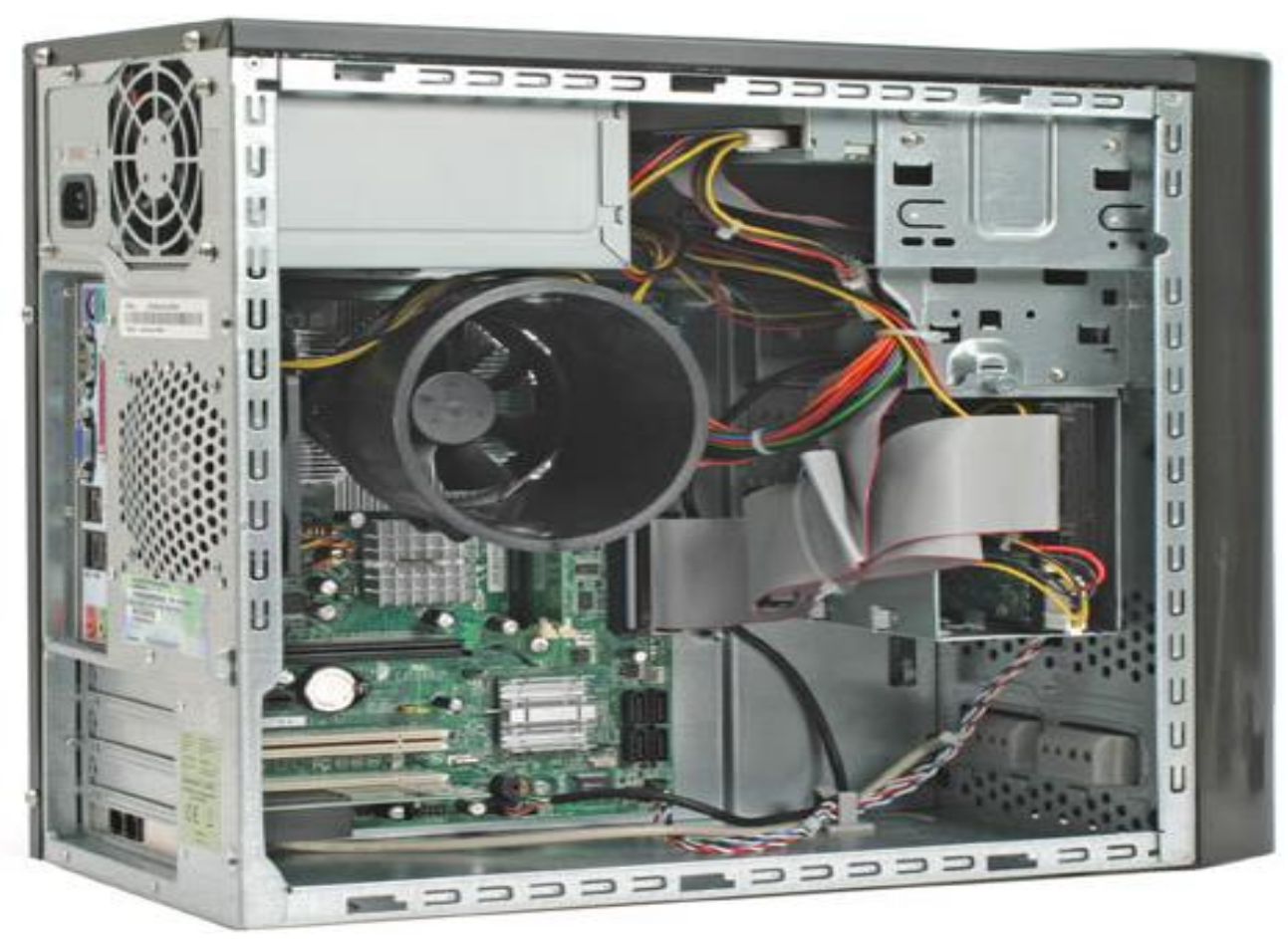

Figure $2:$ A computer case in a classical lab

We can list the hardware and software materials that we use for our test lab that we see fit for this study as follows:

- 10 small computers with ARM processor (5 Raspberry Pi, 3 Banana Pi and 2 Orange Pi)

- Small shelves (boxes) for these devices 
- 10 LCD screens

-Wi-Fi Adapters

- Keyboard and mouses

- Required adapters and cables

- Operating systems for IOT (Windows 10 IoT, Raspbian)

- IDEs for programming (Lazarus, Free Pascal, Atom)

- LibreOffice

If you look at the components on Raspberry Pi 3 Model B, we have a chance to program 40 GPIO (General Purpose IO) pins. We can say this for other single board computers as well. For a brief comparison, see Table 1.

Table 1 : Orange Pi Vs Raspberry Pi 3, Odroid C2 Vs Raspberry Pi 3 Specification

\begin{tabular}{|c|c|c|c|}
\hline Feature & Orange Pi & Odroid C2 & Raspberry Pi 3 \\
\hline CPU & $\begin{array}{l}\text { H5 Quad Core } \\
\text { Cortex-A53 }\end{array}$ & $\begin{array}{l}\text { 1.5GHz Quad Core } \\
\text { ARM Cortex-A53 }\end{array}$ & 1.2GHz 64-bit Quad Core \\
\hline GPU & Mali-450 & Mali-450 & Broadcom VideoCore IV \\
\hline RAM & $\begin{array}{l}\text { 2GB DDR3 } \\
\text { (Shared) }\end{array}$ & 2GB DDR3 SDRAM & 1GB DDR2 \\
\hline Storage & On board & SD Card & SD Card \\
\hline $\begin{array}{l}\text { Ethernet/ WiFi/ } \\
\text { Bluetooth }\end{array}$ & Yes & Only Ethernet & Yes \\
\hline GPIO & $\begin{array}{l}(1 \times 3) \text { UART, } \\
\text { Ground }\end{array}$ & $40+7 \mathrm{I} 2 \mathrm{~S}$ & 40 \\
\hline 4K Compatible & No & Yes & No \\
\hline USB & $\begin{array}{l}3 \text { USB } 2.0,1 \text { USB } \\
2.0 \text { OTG }\end{array}$ & $\begin{array}{l}4 \text { USB } 2.0,1 \text { USB } 2.0 \\
\text { OTG }\end{array}$ & 4 USB 2.0, 1 Micro OTG \\
\hline
\end{tabular}

In Figure 3 you see a Raspberry Pi 3 Model B. As you can see from the Figure, this device is as powerful as the one shown in Figure 2. It takes up less space, less electricity and components are newer.

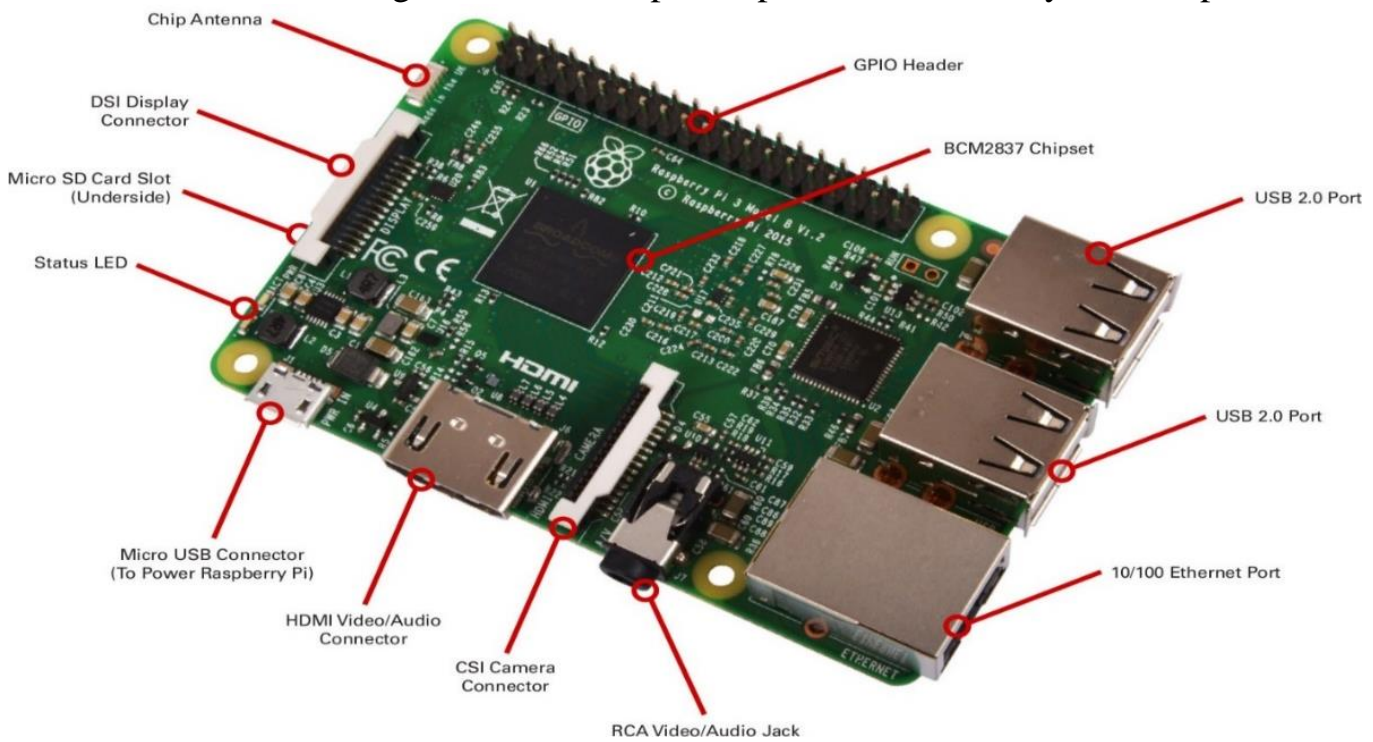

Figure 3: Raspberry Pi 3 Model B [1] 
All the single board computers mentioned here are better and greater than each other in one or another way. The Orange Pi has a wide range of customized boards which can help you to have more specific and detailed design of your project. The Odroid-C2 comes with superfast processor than the other SBCs which is ideal for computing tasks. And the Raspberry Pi models like Pi 2, Pi 3, Pi Zero $\mathrm{W}$, etc. are the most sought, used, tinkered, and gifted single board computers till the date [2].

\subsection{Montages and Installations}

We placed Raspberry Pi and other single board computers in convenient boxes. We connected the LCD screens and wi-fi adapters. Our devices are now ready as hardware. Figure 4 is an image of one of these devices. This device is now ready to install the operating system and other software.

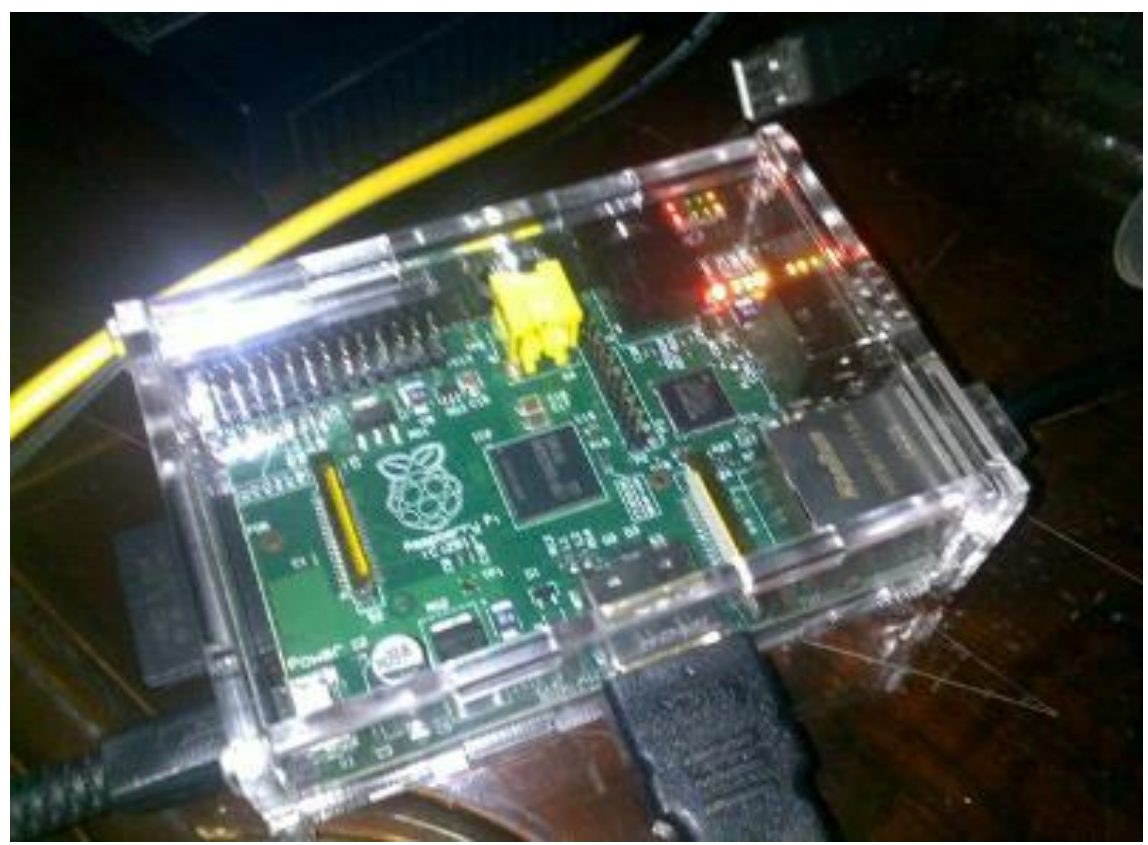

Figure 4 : A mini computer ready for installation.

We started to work on transferring images of my SD Cards, RaspBian (Debian) and Windows 10 for IOT operating systems. [3,4]

We will install SD Card To download the Raspian Jessi operating system, we have connected to https://www.raspberrypi.org/downloads/raspbian/. There are two different files, Raspbain Jessie and Raspbian Jessie Lite. Since there is no graphical display interface in the Lite version, the Raspberry Pi 3 can not receive images from the HDMI output. This version is intended for advanced users to use

Raspberry Pi from the command line (terminal). Those who want to create a project that does not need a screen display prefer the Lite version and control it via SSH connection [3-5].

We printed the image file with the Win32DiskImager program on the SD card. Some of my devices have similarly installed Windows 10 for IOT [3-5].

Windows 10 IoT and RaspBian have installed the following software on the mini-computers:

- Lazarus (Delphi Programming Language alternative)

- LibreOffice (Microsoft Office alternative)

- GIMP (Adobe Photoshop alternative) 
- ATOM (Jetbrains PHPStorm alternative)

- XAMPP Server (Apache + MySQL + PHP + Perl package)

- $\mathrm{C}$ and $\mathrm{C}++$ compilers

- Browsers and other small tools

We completed the setups and completed the configurations. After we installed the SD cards and the minicomputers, we provided the internet and the electrical connections. The devices were ready to work. Figure 5 is an example of this preparation.

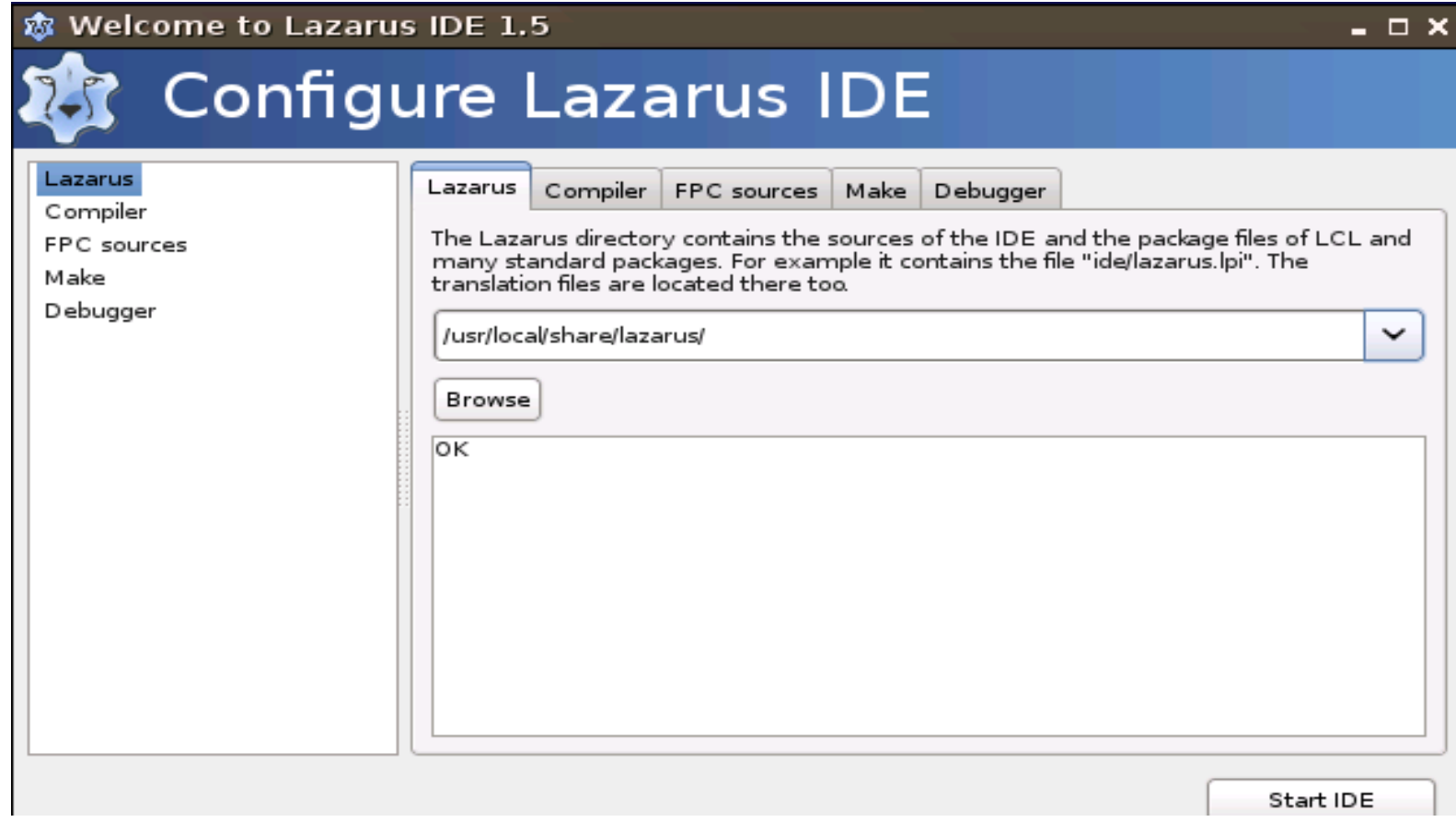

Figure 5: We have installed Lazarus and other software for our mini-computers.

\subsection{Running the System}

We selected 10 students to test the system we set up and see the difference with the other laboratory.

We placed 10 students in the classical laboratory. Both groups gave the same study subjects and we started working on two groups at the same time. We did not tell them you were in a race.

On these computers, students made "Pascal Programming" with Lazarus and "Web Programming with PHP" with ATOM. In the meantime, the necessary graphics were prepared with GIMP. Web pages have been tested on XAMPP. They prepared their documents with LibreOffice. Both student groups worked on $\mathrm{C}$ and $\mathrm{C}++$ using various free IDEs.

\section{RESULTS}

When we compare our work with the results of other laboratories, the results were better. Students work more with pleasure. Expensive devices and software gave them excitement and pleasure. 
The students selected for the test finished most of their work before the other students. As can be seen from Table 2, the test laboratory gave better results in terms of time usage.

Table 2: Comparison of working times

\begin{tabular}{|l|l|l|}
\hline \multicolumn{1}{|c|}{ Working } & \multicolumn{1}{c|}{ Test Lab } & \multicolumn{1}{c|}{ Other Lab } \\
\hline Lazarus (Pascal) Programmming & 3 hours & 2 hours 45 minitues \\
\hline Web Design & 2 hours & 2 hours 15 minitues \\
\hline Office Document & 20 minitues & 25 minitues \\
\hline Graphics & 2 hours & 3 hours \\
\hline Other workings & 4 hours & 6 hours \\
\hline
\end{tabular}

Of course, it is very important that the system is efficient. We did not have a problem in this regard. However, it is also necessary to consider the costs of the systems.

Our test lab was also very cost-effective. While the hardware requirement of our test laboratory is about $4000 \mathrm{TL}$, we have seen that it is more than 7 times that of our other laboratories. In terms of software, it can be expressed by a very low cost in our test laboratory and by a very high figure in the other laboratory. Because all of our testing lab software was free.

\section{CONCLUSION}

We think that working with single-card minicomputers is very enjoyable and motivates the student. We also have the conviction that we can expand and improve as we like, where changes can be implemented more easily.

These computers will be even more attractive when we consider that they can be used in Arduino and other robotic training workshops.

Once we see that the test laboratory we have installed is much less laborious and cost-effective, we find it useful to set up our next laboratories this way. Without compromising the university and the country's budget, we think it is possible to have a good computer education.

\section{REFERENCES}

[1] http://www.robotsepeti.com

[2] https://www.raspberrypistarterkits.com

[3] http://www.samm.com

[4] https://www.raspberrypi.org

[5] http://maker.robotistan.com

[6] https://www.raspi-tr.com

[7] http://www.robotistan.com

[8] https://bigdanzblog.wordpress.com

[9] http://www.makeuseof.com/

[10] Barlow, M.,(2016), Governing the IoT - Balancing Risk and Regulation, O'Reilly Media, Inc., United States of America. 
[11] O'Reilly, T., Doctorow, C., (2015). Opportunities and Challenges in the IoT, O'Reilly Media, Inc., United States of America.

[12] Miller, L., (2017). Internet of Things For Dummies, Qorvo Special Edition, John Wiley \& Sons, Inc., New Jersey

[13] Hung, M., (2015). Leading the IoT (eBook), Published By Gartner.com

[14] daCosta, Francis, Henderson, Byron, (2013). Rethinking the Internet of Things : A Scalable Approach to Connecting Everything, APress, California.

[15] Dunko, G., Misra, J., Robertson, J., Snyder,T.(2017). A Reference Guide to the Internet of Things, Published By Bridgera LLC, North Carolina.

[16] Greengard, S., (2011). The Internet Of Things, The MIT Press, Massachusetts, USA.

[17] Büyüktanır, T., Özer, B.(2017). IoT (Internet Of Things) Nesnelerin Interneti, Kodlab Yayın, İstanbul.

[18] Aktaş, V. (2016).Raspberry Pi,Kodlab Yayın, İstanbul.

[19] Autodesk.com,(2016), THE ESSENTIALS OF IoT FOR MODERN ENGINEERS (eBook), Autodesk.com

[20] Gilbert, J., Weilage, M., Thompson, S., Hammond, T.,(2015), Executive's Guide to IoT and Big Data, Published by TechRepublic, Louisville-Kentucky. 